\title{
Massive pulmonary embolism with extreme hypoxia and hypocarbia caused by knee bandage in young male
}

\author{
Ümit Yaşar Sinan', Uğur Coşkun ${ }^{1}$, Gürkan İmre', Cem Bostan¹, Okay Abacı1, \\ Cüneyt Kocaş ${ }^{1}$, Şükrü Arslan', Onur Baydar ${ }^{1}$, Veysel Oktay ${ }^{1}$, Serdar Küçükoğlu ${ }^{1}$
}

1) Istanbul University Institute of Cardiology, Cardiology Department, Istanbul, Turkey

\section{Summary}

Pulmonary embolism (PE) caused by obstruction of the pulmonary arterial bed is an acute, life threatening, cardiovascular emergent situation. It is a reversible cause of right ventricular failure. The initial diagnosis majority may be missed due to symptoms and signs are nonspecific. Because of late detection of diagnosis is fatal, PE should be thought when acute dyspnea occurs. PE and deep vein thrombosis (DVT) are clinical situations related to venous thromboembolism (VTE). PE accompanies 50\% to DVT. ${ }^{(1)}$ The real incidence of DVT and PE is not known due to nonspecific clinical situation. Pulmonary embolism occurs in $0.4 \%$ of hospitalized patients. ${ }^{(2)}$

Keywords: Pulmonary embolism, deep vein thrombosis, ventricular failure.

\section{Case}

A 34 years old professional basketball player was admitted to our emergency service with ambulance service due to acute dyspnea. The dyspnea had started suddenly after basketball training and the general condition of the patient has rapidly deteriorated. The patient had an injury of left knee anterior cruciate ligament two month ago. A knee bandage had been advised by an orthopedist. Except this injury there was no special characteristic on his background. On physical examination, he was unconscious and extremely cyanotic. He had severe dyspnea and tachypnea. First and second heart sound were normal, but there was right ventricular third heart sound (S3) and jugular venous distention. The blood pressure was $80 / 50 \mathrm{mmHg}$. The ECG 
showed S1Q3T3 pattern. There was a bandage on his left knee. Also on the left thigh there was swelling and stiffness. The artery blood gas showed extreme hypoxia, hypocarbia and deep acidosis (Figure 1).

On laboratory examination D-dimer was extremely high. Transthoracic echocardiography (TTE) revealed right ventricular dilatation (RV diameter:3.47 cm), systolic dysfunction (TAPSE:0.92 $\mathrm{cm}$ and tricuspid valve lateral annulus systolic velocity: $0.7 \mathrm{~cm} / \mathrm{sec}$ ), and high estimated systolic pulmonary artery pressure (sPAP:55 $\mathrm{mmHg}$ ) (Figure 2 and 3 ). Finally we suspected strongly acute pulmonary emboli. The patient was considered at high risk of PE due to hemodynamic instability. So we decided urgently to start intravenous thrombolytic therapy. He was intubated because of poor blood gasses results. $100 \mathrm{mg}$ t-PA was given in two hours. Unfractionated heparin (UFH) was started with t-PA and continued after thrombolytic therapy. After thrombolytic therapy the hemodynamic situation and artery blood sample were improved (Figure 4). The patient was extubated.

When he was stable, pulmonary $\mathrm{CT}$ angiography

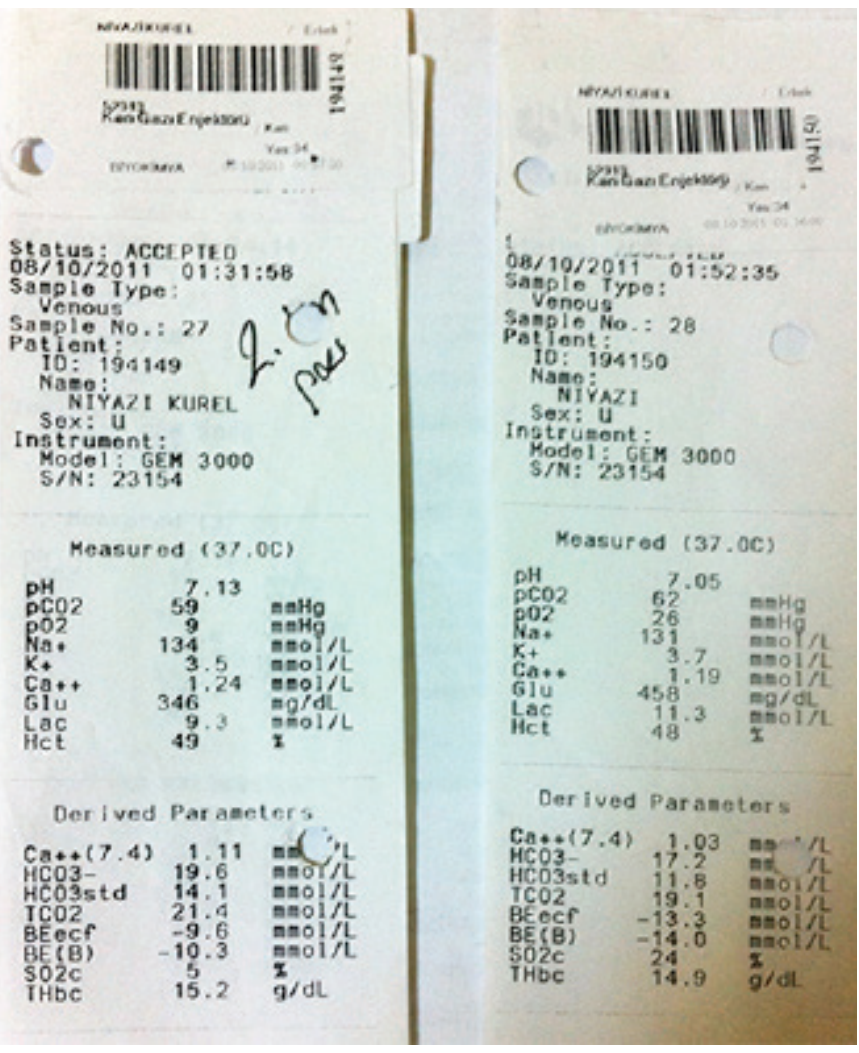

Figure 1. Initial blood gases results. was performed. Huge thrombus bulks were observed in both the pulmonary artery and distal branches. Warfarin was started to patient. Bilateral lower extremities venous Doppler and coagulation parameters (Factor Leiden $\mathrm{V}$, protein $\mathrm{C}$ and $\mathrm{S}$ etc.) were normal. So we thought that the PE was secondary to venous blood restriction by knee bandage and decided to give warfarin therapy for six months. The patient was discharged without complaint to be followed up as outpatients.

\section{Discussion}

Pulmonary embolism (PE) caused by obstruction of the pulmonary arterial bed is an acute, life threatening,

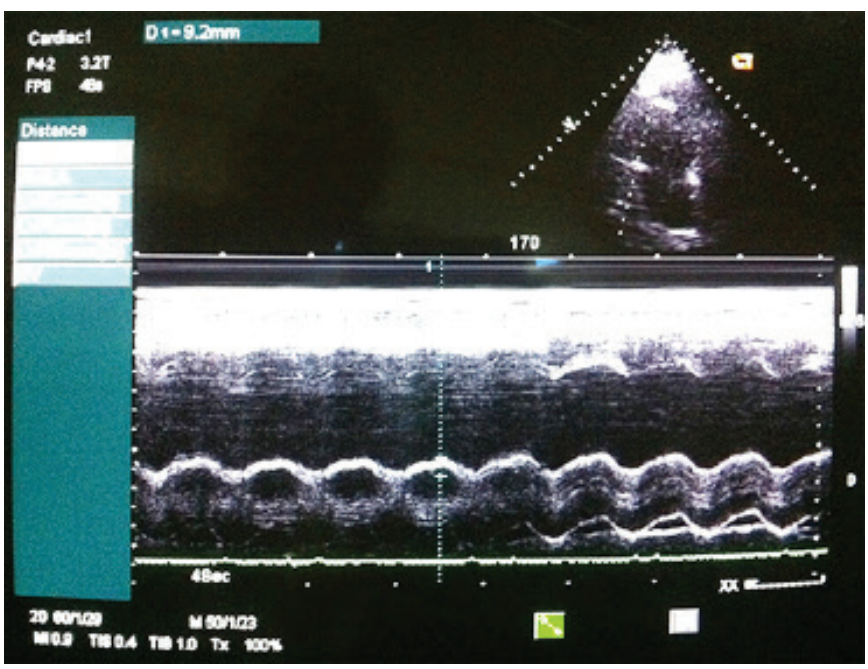

Figure 2. Right ventricular enlargement in transthoracic echocardiography parasternal long axis view.

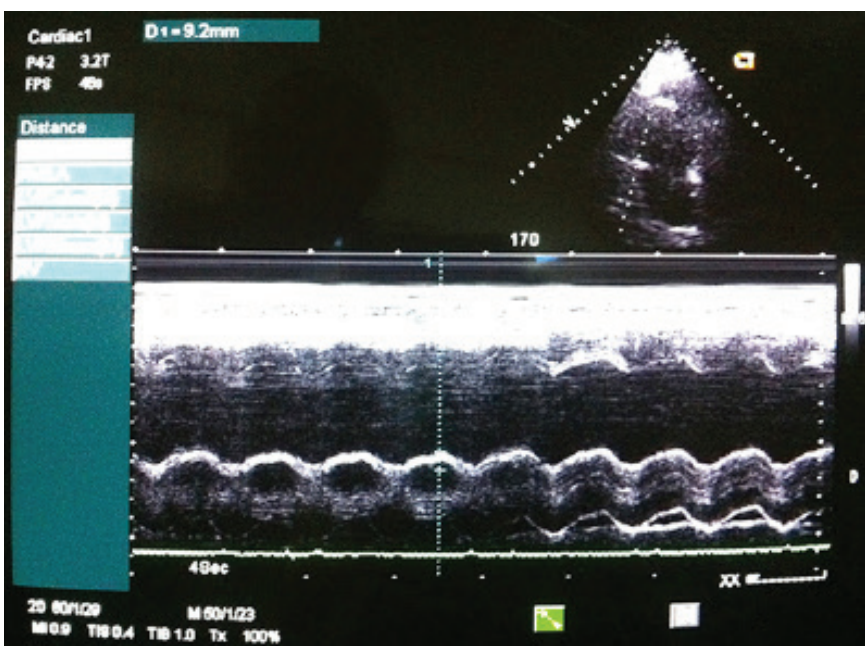

Figure 3. Decreased TAPSE in transthoracic echocar diography. 
cardiovascular emergent situation. PE and deep vein thrombosis (DVT) are clinical situations related to venous thromboembolism (VTE). On patients who admit-

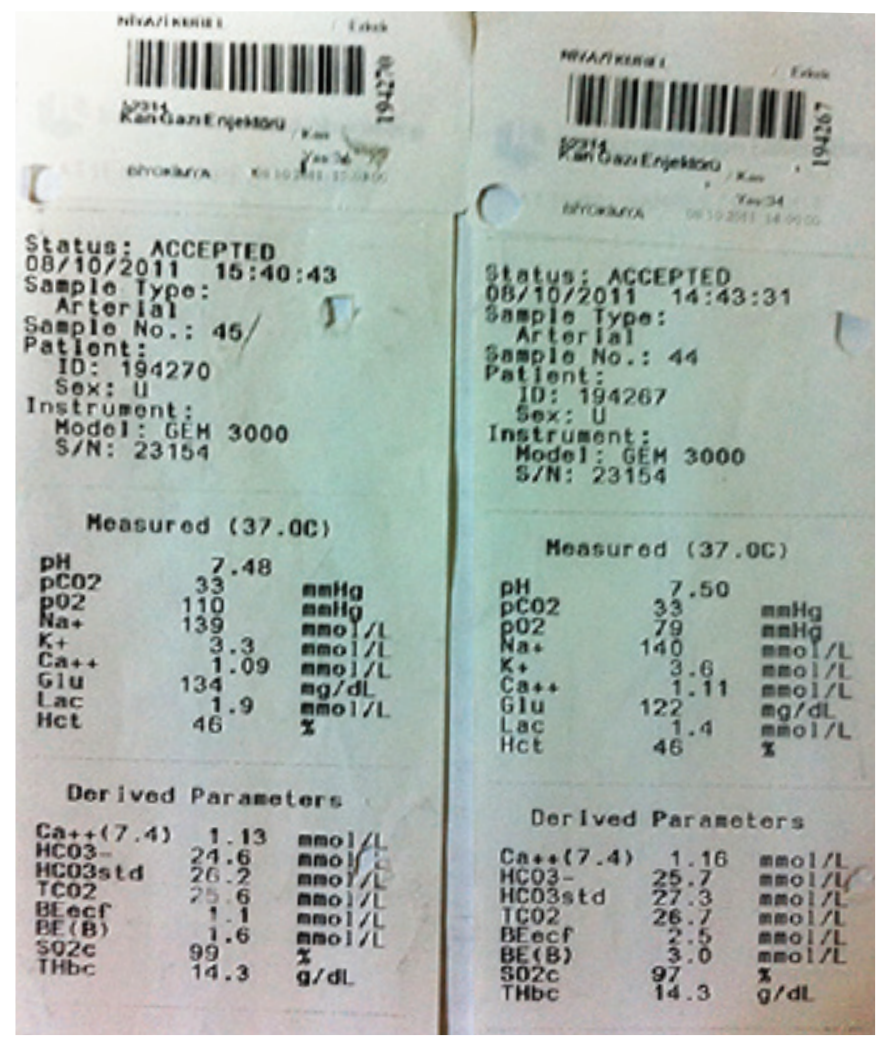

Figure 4. After thrombolytic therapy and extubation blood gases results.

\section{References}

1. Moser KM, Fedullo PF, Littejohn JK, Crawford R. Frequent asymptomatic pulmonary embolism in patients with deep venous thrombosis. JAMA 1994;271:223-5.

2. Stein PD, Beemath A, Olson RE. Trends in the incidence of pulmonary embolism and deep venous thrombosis in hospitalized patients. Am J Cardiol 2005;95:1525-6.

3. Dalen JE. Pulmonary embolism: what have we learned since Virchow? Natural history, pathophysiology, and diagnosis. Chest 2002;122:1440-56.

4. Goldhaber SZ, Visani L, De Rosa M. Acute pulmonary embolism: clinical outcomes in the International Cooperative Pulmonary Embolism Registry (ICOPER). Lancet 1999;353:1386-9.

5. Guidelines on the diagnosis and management of acute pulmonary embolism. European Heart Journol 2008;29:2276-315. ted to the clinic with PE, DVT is the underlying cause of $\% 70$ as a result of further investigations. ${ }^{(3)}$

In the presence of a number of predisposing factors that facilitate the exit is called secondary PE. If there is any underlying cause is called idiopathic PE. Compose $20 \%$ of all cases were idiopathic PE according to ICOPER. ${ }^{(4)}$ Facilitating factors that are associated with the patient or conditions include certain; advanced age, prior VTE, active malignancy, neurological disease with extremity paralysis such as heart disease and respiratory failure situations that require a long time immobilization, congenital or acquired thrombophilia, hormone replacement therapy (HRT) or combined oral contraceptive treatment, hip or leg fracture, hip or knee joint replacement, major surgery and trauma. ${ }^{(5)}$

\section{Conclusion}

In our patient there was no any immobilization history. But he had history of knee injury. Although it did not cause immobilization there was a bandage on his knee which restricting venous blood flow. So we keep in mind that deep vein thrombosis and PE may be occurred without immobilization.

Received: $14 / 12 / 2013$

Accepted: 22/03/2014

Published: 15/09/2014

Disclosure and conflicts of interest:

Conflicts of interest were not reported.

\section{Corresponding author:}

Dr. Umit Yasar Sinan

umityasarsinan@gmail.com 